\title{
Antiviral activity of medicinal plants extracts against foodborne Norovirus
}

\author{
IVANA ŽıvKović ${ }^{1}$, KATARINA ŠAVIKIN ${ }^{2}$, GordanA Zdunić ${ }^{2}$, JELENA ŽıVKović ${ }^{2}$, DubravkA \\ Bigović $^{2}$, NebojŠa Menković ${ }^{2}$, and Dragoslava Radin ${ }^{1, *}$ \\ ${ }^{1}$ University of Belgrade - Faculty of Agriculture, Institute for Food Technology and Biochemistry, Nemanjina 6, 11080 Belgrade, Serbia \\ ${ }^{2}$ Institute for Medicinal Plants Research "Dr. Josif Pančić", 11000 Belgrade, Serbia \\ *Corresponding author: dradin@agrif.bg.ac.rs
}

Received: October 30, 2018

Accepted: November 20, 2018

Published on-line: December 20, 2018

Published: December 25, 2018

\begin{abstract}
Medicinal plant extracts (MPE) have a broad antimicrobial activity, including antiviral effects. In our study, eleven dry extracts of ten different medicinal plants prepared with two solvents $(5 \%$, dimethyl sulfoxide (DMSO) and 30\% ethanol in 5\% DMSO) in different concentrations have been examined for anti-norovirus activity. The reduction of norovirus $>1 \log _{10}$ genome equivalents (GE) has been obtained with $1 \mathrm{mg} / \mathrm{mL}$ of Aronia melanocarpa leaf extract (AMLE), dried wine Prokupac (WPE) and Hypericum perforatum extract (HyPE). Some of MPE i.e. HyPE, Aronia melanocarpa fruit extract (AMFE) and Punica granatum peel extract (PPE) showed better activity when dissolved in $30 \%$ ethanol with $5 \%$ DMSO. All results of anti-noroviral activity of tested MPE which achieve $<0.5 \log _{10}$ GE are considered as not effective.
\end{abstract}

Key words: Human norovirus, medicinal plant extract, antiviral activity

http://dx.doi.org/10.5937/leksir1838031Z

\section{INTRODUCTION}

Generally, human norovirus ( $\mathrm{hNoV}$ ) is recognized as one of the most common causes of viral gastroenteritis. Norovirus is easily transmitted from person to person by a fecal-oral route directly or indirectly through contaminated food (shells, berries, etc) or water. Also, hNoV are very often related with fresh products and large outbreaks are well documented (EFSA/ECDC, 2016). The European Union (EU) Rapid Alert System for Food and Feed (RASFF) indicated that norovirus is a relatively "new acquaintance" in terms of citation history in RASFF border rejection notifications (involving Third Countries as countries of origin) but a rather "old acquaintance" in alert notifications. The relative frequency of citation of alert notifications on norovirus places them well ahead of Salmonella and Listeria, well known bacterial food pathogens, and marks those foodborne viruses as a serious biological hazard (Papapanagiotou, 2017).

Norovirus belongs to the Caliciviridae family of non-enveloped, small, positive-stranded RNA viruses and based on their capsid amino acid compositions are divided into 6 genogroups (GI - GVI) and > 40 genotypes (Rocha-Pereira et al., 2016). $\mathrm{HNoV}$ as non-enveloped viruses are resistant to the majority of chemical disinfectants. One of the agents with virucidal efficacy is chlorine/hypochlorite, however due to its byproducts represents health risk (El-Senousy et al., 2014).

Numerous plants have been used in traditional medicine for healing but also for the preservation of raw and processed food (Jaykus et al., 2013; D'Souza, 2014). Plant extracts abundant in chemically diverse metabolites have been extensively studied for their varied biological activity including antimicrobial (Braga et al., 2005; D'Souza, 2014). Plant derived antimicrobials for the control and prevention of the transmission of human enteric viruses, including noroviruses, are of recent interest especially because of the absence of vaccines for the human noroviruses. The aim of our study was screening of dry extracts of ten different medicinal plants for anti-norovirus activity.

\section{MATERIALS AND METHODS}

\subsection{HNoVstock}

Fecal stool samples containing hNoV were diluted (w/v) to obtain $10 \%$ suspensions with phosphate buffered saline (PBS, $\mathrm{pH}=7.2)$. Suspensions were centrifuged (Eppendorf $5804 \mathrm{R}$ $14000 \mathrm{G} / 5 \mathrm{~min}$ at $20^{\circ} \mathrm{C}$ ) and filtered using syringes ( 0.45 and $0.22 \mu \mathrm{m}$ filter pore size; Thermo Fisher Scientific, Germany) in order to remove impurities. Target hNoV RNA (expressed as amount of genome equivalents; GE) in the suspension was quantified by standard curve which was prepared using positive control (PC) template (Quantification of Norovirus genotype 1 and 2, Primer DesignTM Ltd, genesig). The all further experiments were carried out with the $1 \%$ suspension of $\mathrm{hNoV}$ which contained $\approx 10^{5}$ GE per $\mu \mathrm{L}$. 
Table 1. Medicinal plants used for the testing of antiviral activity

\begin{tabular}{lcc}
\hline Extracts & Abbreviation & Plant part \\
\hline Sideritis raeseri & SRE & Herba \\
Gentiana asclepiadea & GAE & Root \\
Aronia melanocarpa & AMLE & Leaf \\
Gentiana lutea & GLE & Root \\
Helichrysum plicatum & HPE & Herba \\
Hypericum perforatum & HyPE & Herba \\
Aronia melanocarpa & AMFE & Fruit \\
Satureja subspicata & SSE & Herba \\
Mahonia aquifolia & MAE & Peel \\
Punica granatum & PPE & Peel \\
Vitis vinifera, var. Prokupac & WPE & Wine \\
\hline
\end{tabular}

\subsection{Medicinal plants extract (MPE)}

After drying at room temperature plant material was milled in a laboratory mill. Extraction was done using maceration with $70 \%$ ethanol (EtOH). The extracts were then filtered and the solvent was evaporated under low pressure at temperature not higher than $50^{\circ} \mathrm{C}$. Wine of the grape variety Prokupac was also evaporated to dryness under vacuum. Dry extracts were kept in a vacuum desiccator until analysis. Medicinal plants and their parts used for testing are listed in Table 1.

\subsection{Antiviral activity of MPE}

MPE have been diluted with two solvents: 5\% dimethyl sulfoxide (DMSO) and combination of 30\% ethanol in 5\% DMSO to obtain final concentrations of $0.4 ; 1.0$ and $2.5 \mathrm{mg} / \mathrm{mL}$. To test the antiviral activity of MPE the equal volumes of $\mathrm{hNoV}$ and extracts suspensions have been mixed and incubated $1 \mathrm{~h}$ at $37^{\circ} \mathrm{C}$. Solvents used for MPE preparation (5\% DMSO, mixture of $30 \%$ ethanol in 5\% DMSO) have been tested to confirm that they themselves have no effect on the reduction of $\mathrm{hNoV}$ particles.

\subsection{Disinfectant solution and experimental treatment with hNoV suspension}

Commercial household bleach was purchased at a local store (Belgrade, Serbia). The main ingredient of the bleach was sodium hypochlorite $(\mathrm{NaOCl}, 4.5 \%[\mathrm{w} / \mathrm{v}])$. Experimental sodium hypochlorite solution was diluted with dimethyl sulfoxide ( $5 \%$ DMSO) to $250 \mathrm{ppm}$ and $25 \mathrm{ppm}$ free chlorine concentration. Equal volumes of $\mathrm{hNoV}$ suspension and disinfectant solution have been mixed and incubated $1 \mathrm{~h}$ at $37^{\circ} \mathrm{C}$. Because of the possible aggression of free chlorine on isolation of hNoV RNA with commercial kit, the direct method with TRIzol $^{\mathrm{TM}}$ reagent has been used (Radin and D'Souza, 2011).

\subsection{RT-qPCR assays}

One-Step RT-qPCR assays were performed using $20 \mu \mathrm{L}$ reaction mixture containing $10 \mu \mathrm{L}$ of oasig TM qRT-PCR MasterMix, $1 \mu \mathrm{L}$ of Norovirus Primer/Probe mix and hNoV RNA sample. No-template control (NTC) was added to verify the absence of contamination. Cycling conditions for RT-qPCR were as follows: reverse transcription at $55^{\circ} \mathrm{C} / 10 \mathrm{~min}$, enzyme activation $95^{\circ} \mathrm{C} / 2 \mathrm{~min}$, denaturation at $94^{\circ} \mathrm{C} / 12 \mathrm{~min}$,followed by 50 cycles. RT-qPCR assays were done using Quantification of Norovirus genotype I and II (PrimerTMLtd, genesing, United Kingdom).

\section{RESULTS AND DISCUSSION}

\subsection{Reduction of hNoV in suspension by medicinal plant extracts}

Antiviral activity of 10 medicinal plant extracts applied at different concentrations $(0.4,1.0,2.5 \mathrm{mg} / \mathrm{mL})$ and dissolved in two different solvents has been examined for the reduction of foodborne $\mathrm{hNoV}$ particles in suspension following treatment at $37{ }^{\circ} \mathrm{C}$ during $1 \mathrm{~h}$ (Table 2). The reduction of norovirus $>1 \log _{10}$ GE has been obtained with $1 \mathrm{mg} / \mathrm{mL}$ of Aronia melanocarpa leaf extract (AMLE), dried wine Prokupac (WPE) and Hypericum perforatum (HyPE) extract, and therefore could be promising for $\mathrm{hNoV}$ reduction having in mind that tested concentrations have been lower than usually used. The reduction in the interval $0.5-1 \log _{10}$ GE has been obtained with $0.4 \mathrm{mg} / \mathrm{mL}$ of WPE, PPE and HyPE; $1.0 \mathrm{mg} / \mathrm{mL}$ of GAE and AMFE; $2.5 \mathrm{mg} / \mathrm{mL}$ of GAE and AMFE. All results of antinoroviral activity of tested MPE which achieve $<0.5 \log _{10}$ GE are considered as not effective. Some of MPE i.e. HyPE, Aronia melanocarpa fruit extract (AMFE) and Punica granatum (PPE) showed better activity when dissolved in 30\% ethanol with $5 \%$ DMSO.

According to the literature, this is the first report of the antinorovirus activity of Aronia melanocarpa. Antiviral activity of A. melanocarpa on some other viruses was reported. Park et al. (2013) reported that fruits of $A$. melanocarpa possess in vitro and in vivo activity against different subtypes of influenza viruses and such activity was also noticed for oseltamivir-resistant strain. They concluded that the activity was attributed to two constituents i.e. ellagic acid and myricetin.

Moreover, this is the first report of the anti-norovirus activity of the wine obtained from Serbian autochthonous grape variety Prokupac. It is in accordance with the Oh et al. (2015) findings that red wine as well as its component resveratrol can affect the foodborne viral surrogates, murine norovirus- 1 and feline calicvirus Fs at an early stage of infection.

As for Hypericum species, Akram et al. (2018) assembled the facts from articles published in English language since 1982 to 2017 about antiviral potential of plants in various viral diseases such as influenza, hepatitis, human immunodeficiency virus (HIV), herpes simplex virus (HSV), etc. which have been proven in clinical studies. One of the species which was pointed out for its activity was Hypericum connatum. Also, antiviral activity was reported for other Hypericum species (de Carvalho Meirelles et al., 2019).

\subsection{Virucidal effects of disinfectant solution against hNoV particles}

As one kind of control, proven effective disinfectant against $\mathrm{hNoV}$ has been tested for the reduction of virus particles. Commercial household bleach containing sodium hypochlorite $(\mathrm{NaOCl}, 4.5 \%$ [w/v]) was diluted with dimethyl sulfoxide (5\% DMSO) to $250 \mathrm{ppm}$ and $25 \mathrm{ppm}$ free chlorine concentrations. Equal volumes of hNoV suspension and disinfectant solution have been mixed and incubated $1 \mathrm{~h}$ at $37^{\circ} \mathrm{C}$. At lower concentration disinfectant solution have reduced $\mathrm{hNoV}$ particles at the level of $0.62 \pm 0.01 \log _{10}$ GE similar as some of MPE. The higher concentration of disinfectant solution showed significant reduction of hNoV particles at level of $2.40 \pm 0.02 \log _{10}$ GE.

Similar results have been published by Kingsley et al. (2014) concluding that free chlorine treatments at concentrations of 33 and 189 ppm reduced hNoV binding in the PGM-MB assay by 1.48 and $4.14 \log _{10}$, while $1 \mathrm{~h}$ treatment with $350 \mathrm{ppm}$ chlorine dioxide reduced $\mathrm{hNoV}$ by $2.8 \log _{10}$. According to Codex Alimentarius (2012) a biocide is considered effective when the $\log$ reduction of the infectious viral titer is $>3 \log _{10}$. 
Table 2. Antiviral activity of medicinal plants extracts against foodborne norovirus after treatment at $37^{\circ} \mathrm{C} 1 \mathrm{~h}$

\begin{tabular}{|c|c|c|c|c|c|}
\hline \multirow[b]{7}{*}{ Extract } & \multicolumn{5}{|c|}{ Concentration of medicinal plants extracts } \\
\hline & \multirow{2}{*}{\multicolumn{2}{|c|}{$\begin{array}{c}0.4 \\
{[\mathrm{mg} / \mathrm{mL}]}\end{array}$}} & \multicolumn{2}{|c|}{1} & \multirow{2}{*}{$\begin{array}{c}2.5 \\
{[\mathrm{mg} / \mathrm{mL}]}\end{array}$} \\
\hline & & & {$[\mathrm{mg} /$} & & \\
\hline & \multirow[t]{2}{*}{$5 \% \mathrm{DMSO}^{\mathrm{a}}$} & $5 \%$ DMSO & $5 \%$ DMSO & $5 \%$ DMSO & \multirow[t]{2}{*}{$5 \%$ DMSO } \\
\hline & & $+30 \% \mathrm{EtOH}$ & & $+30 \% \mathrm{EtOH}$ & \\
\hline & \multicolumn{5}{|c|}{ Reduction of $\mathrm{hNoV}^{\mathrm{b}, \mathrm{c}, \mathrm{d}}$} \\
\hline & \multicolumn{5}{|c|}{ [ $\log _{10}$ genome equivalents] } \\
\hline SRE & $0.33 \pm 0.01$ & NR & $0.28 \pm 0.03$ & - & - \\
\hline GAE & $0.49 \pm 0.04$ & - & $0.59 \pm 0.01$ & - & $0.79 \pm 0.07$ \\
\hline AMLE & $0.45 \pm 0.02$ & - & $1.06 \pm 0.05$ & - & - \\
\hline GLE & $0.45 \pm 0.01$ & - & $0.46 \pm 0.01$ & - & $0.26 \pm 0.04$ \\
\hline WPE & $0.79 \pm 0.02$ & $0.30 \pm 0.01$ & $1.21 \pm 0.01$ & - & - \\
\hline HPE & - & $0.48 \pm 0.03$ & $0.22 \pm 0.02$ & - & $0.32 \pm 0.01$ \\
\hline HyPE & $\mathrm{ND}$ & $0.93 \pm 0.01$ & $\mathrm{ND}$ & $1.38 \pm 0.01$ & - \\
\hline AMFE & $0.12 \pm 0.03$ & $0.28 \pm 0.03$ & $0.29 \pm 0.05$ & $0.66 \pm 0.02$ & $0.55 \pm 0.02$ \\
\hline SSE & $0.23 \pm 0.01$ & NR & NR & - & $0.13 \pm 001$ \\
\hline MAE & NR & - & $0.21 \pm 0.01$ & - & NR \\
\hline PPE & $0.70 \pm 0.03$ & $0.83 \pm 0.03$ & - & - & - \\
\hline
\end{tabular}

\section{CONCLUSION}

In conclusion, the most active extracts were Aronia melanocarpa leaves extract, Hypericum connatum extract, and dried Prokupac wine. It was noticed that the type of solvent used for dissolution made a significant difference in anti-noroviral activity. Some of the medicinal plant extracts showed anti-noroviral activity similar to the effect of lower concentration of sodium hypochlorite that stands as one of the few efficient chemical disinfectants but with byproducts that could be health hazardous.

\section{ACKNOWLEDGMENTS}

Acknowledgment. This work was supported by the Ministry of Education, Science and Technological Development Republic of Serbia (Projects III 46009 and III 46013).

\section{REFERENCES}

Akram, M., Tahir, I. M., Shah, S. M. A., Mahmood, Z., Altaf, A., Ahmad, K., Munir, N., Daniyal, M., Nasir, S. and Mehboob, H. (2018). Antiviral potential of medicinal plants against HIV, HSV, influenza, hepatitis, and coxsackievirus: A systematic review, Phytotherapy Research 32(5): 811-822.

Braga, L., Shupp, J., Cummings, C., Jett, M., Takahashi, J., Carmo, L., Chartone-Souza, E. and Nascimento, A. (2005). Pomegranate extract inhibits Staphylococcus aureus growth and subsequent enterotoxin production, Journal of Ethnopharmacology 96(1-2): 335-339.

Codex Alimentarius (2012). CAC/GL 79-2012 guidelines on the application of general principles of food hygiene to the control of viruses in food, Codex Committee on Food Hygiene 13.

de Carvalho Meirelles, G., Bridi, H., Rates, S. M. K. and von Poser, G. L. (2019). Southern Brazilian Hypericum Species, Promising Sources of Bioactive Metabolites, Studies in Natural Products Chemistry, Vol. 59, Elsevier, pp. 491-507.
D'Souza, D. H. (2014). Phytocompounds for the control of human enteric viruses, Current Opinion in Virology 4: 44-49.

EFSA/ECDC (2016). The european union summary report on trends and sources of zoonoses, zoonotic agents and food-borne outbreaks in 2015, The EFSA Journal 14(12): 4634.

El-Senousy, W. M., El-Gamal, M. S., Mousa, A. A. E.-B., ElHawary, S. E.-S., Kamel, M. M., Fathi, M. N. and El-Mahdy, E.-M. M. (2014). Effect of Chlorine on Noroviruses, Rotaviruses and Hepatitis E Virus in Drinking Water, World Applied Sciences Journal 32(11): 2206-2212.

Jaykus, L., D'Souza, D. and Moe, C. (2013). Foodborne viruses, in M. Doyle and R. Buchanan (eds), Food Microbiology Fundamentals and Frontiers, ASM Press, Washington, DC, USA.

Kingsley, D. H., Vincent, E. M., Meade, G. K., Watson, C. L. and Fan, X. (2014). Inactivation of human norovirus using chemical sanitizers, International Journal of Food Microbiology 171: 94-99.

Oh, M., Lee, J.-H., Bae, S. Y., Seok, J. H., Kim, S., Chung, Y. B., Han, K. R., Kim, K. H. and Chung, M. S. (2015). Protective effects of red wine and resveratrol for foodborne virus surrogates, Food Control 47: 502-509.

Papapanagiotou, E. (2017). Foodborne Norovirus State of Affairs in the EU Rapid Alert System for Food and Feed, Veterinary Sciences 4(4): 61.

Park, S., Kim, J. I., Lee, I., Lee, S., Hwang, M.-W., Bae, J.-Y., Heo, J., Kim, D., Han, S.-Z. and Park, M.-S. (2013). Aronia melanocarpa and its components demonstrate antiviral activity against influenza viruses, Biochemical and Biophysical Research Communications 440(1): 14-19.

Radin, D. and D'Souza, D. H. (2011). Simple and Rapid Detection of Human Norovirus from Produce Using SYBR Green I-based Real-time RT-PCR, Food and Environmental Virology 3(3-4): 121-129. 
Rocha-Pereira, J., Van Dycke, J. and Neyts, J. (2016). Norovirus genetic diversity and evolution: implications for antiviral therapy, Current Opinion in Virology 20: 92-98. 